\title{
The Study on Leakage Current Characteristics and Electrical Properties of Uncoated Ceramic, RTV Silicon Rubber Coated Ceramic, and Semiconducting Glazed Outdoor Insulators
}

\author{
Rachmawati, Nike Sartika, Naufalarizqa Ramadha Meisa Putra, and Suwarno \\ School of Electrical Engineering and Informatics \\ Institut Teknologi Bandung \\ Bandung, Indonesia \\ rachmawati@stei.itb.ac.id ; suwarno@stei.itb.ac.id
}

Abstract: Insulator is one of the most important equipment in an electric power system. Failure of insulator may interrupt the electric energy delivery. The system reliability is greatly affected by the performance of the insulator. Therefore, ensuring the high performance of insulators has become indispensable. There are many methods to increase the performance of the outdoor insulator that are exposed to environmental conditions, such as temperature, humidity, and the presence of pollutants. Among the methods, applying room temperature vulcanized (RTV) silicone rubber coating and semiconducting glaze on the insulator surface are often used. This paper discusses the performance of uncoated ceramic insulator, RTV silicone rubber coated insulator, and semiconducting glazed insulator (SGI), as well as the comparison result among them. The performance is indicated by measuring leakage current (LC), surface temperature, and hydrophobicity. In addition, computer simulation on outdoor insulators using ATPDraw software is also conducted for LC waveform resulted by each type of insulator in order to study the electrical properties of each insulator. In the simulation, an outdoor insulator is represented by an electrical circuit model consisting of capacitors, nonlinear resistors, and number of arc models. AC voltage is applied to the model and the current is monitored. Hence, some key parameters of LC waveform are required to determine the similarity between measured LC waveform and simulated LC waveform, which are LC magnitude, Total Harmonic Distortion (THD), and dominant harmonic number. Experiment result shows that LC waveform and magnitude are strongly affected by the applied voltage, environmental condition, and the condition of the insulator surface itself. Specifically for SGI, LC waveforms are generally similar with the sinusoidal applied voltage. The LC waveforms are also symmetrical for positive and negative half cycles and no flashover was observed for applied voltage up to $40 \mathrm{kV}$. The hydrophobicity of insulator surface decreases after the experiments, with the pollutant presence and salt fog condition cause higher reduction compared to the clean samples and in clean fog environment. SGI has higher hydrophobicity compared to ceramic insulator. Field-aged RTV silicone rubber coated insulator shows higher hydrophobicity compared to field-aged uncoated ceramic insulator. At the end of the $6^{\text {th }}$ year, the difference of contact angle between the two types of insulators can reach up to $50-60^{\circ}$. This proves that less pollutant is likely to stick on coated insulators for long time.

The LC waveforms obtained from all experiments both in the laboratory or in the field have been successfully simulated through computer simulation. The simulation indicated that SGI is more capacitive than normal ceramic insulator and has lower values of piecewise resistance of the nonlinear resistance, resulting LC flow on the insulator surface also much higher. Despite the increased applied voltage, SGI shows very little discharge on its LC waveform, hence it has only 2 arc models, while at higher applied voltage, ceramic insulator has many discharges occur along the LC waveform, hence the arc models for this insulator can reach up to 9 arc models.

Received: January $24^{\text {th }}, 2018$. Accepted: June $23^{\text {rd }}, 2018$

DOI: 10.15676/ijeei.2018.10.2.9 
Keywords: outdoor insulator, ceramic insulator, RTV silicone rubber; semiconducting glazed; coating; leakage current waveform; electrical equivalent circuit; computer simulation; total harmonic distortion

\section{Introduction}

Failed insulators can cause the interruption in the electrical power delivery which leads to greater loss to the whole power transmission system. Outdoor insulator is a type of insulator that often experiences failures, where environmental factors including humidity, temperature, and pollution can have a great impact on the insulators performance [1-2]. On polluted insulator surface, flashover is initiated by the presence of conductive layer that is formed and causing increased leakage current, especially in humid atmosphere.

Ceramic insulators are beneficial as outdoor insulators to be installed in such industrial area or coastal area. Apart from being economical, it has good electrical properties, such as thermal resistance and resistance to surface degradation (corrosion), as well as good mechanical properties [3-6]. In addition, this ceramic insulator has a glass-like layer that allows the insulator to perform self-cleaning process with the help of rain water. In Indonesia, especially in Bali, ceramic insulators have been the most widely used type of insulators for transmission and distribution systems for a long time. Nevertheless, with the constant stress along the years, surface resistance of outdoor ceramic insulators can easily decrease due to the environmental factors, most of all is the pollutant and eventually leads to complete failure [6].

Many alternative solutions have been offered to overcome this situation, such as applying RTV silicone rubber coating or semiconducting glazed layer on the insulator surface. RTV silicone rubber coating has been proven that it can reduce LC magnitude. Hence, the aging effect on insulators performance can be reduced. Another type of coating material, semiconducting glazed insulator (SGI) has been proven to have higher flashover voltages compared to normal glazed porcelain or glass insulator, mainly due to the surface drying effect by LC flow on the glazed layer [7]. The special glazing can prevent dry band formation and therefore dry band arcing which often causes the flashover of the insulator [8]. High temperature of insulator surface that is caused from leakage current on semiconducting glazed layer prevent condensation and humidity effect [9].

This paper discusses the experiment results of ceramic insulators and SGI under artificial condition in laboratory that is made resembling to environmental condition in Bali. Another experiment result which is carried on at the field of coastal area at Pangandaran (southern of West Java island) is also reported, consisting of LC measurement result on field-aged RTV silicone rubber coated and uncoated insulators, including LC magnitude, Total Harmonic Distortion (THD), and dominant harmonic of each waveform, in which these parameters become the key for further simulation.

\section{Experiment and Simulation}

A. Laboratory Test for Ceramic and Semiconducting Glazed Insulators(SGI)

Both ceramic insulator and SGI used in this research are suspension-type insulators that have been used in Indonesia $150 \mathrm{kV}$ transmission lines. For each type, there are two samples used in this experiment, where one has clean surface and the other one has polluted surface as shown in Figure 1 [10-11]. 


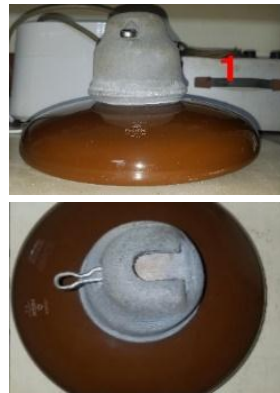

(a) Clean surface

- Ceramic insulator

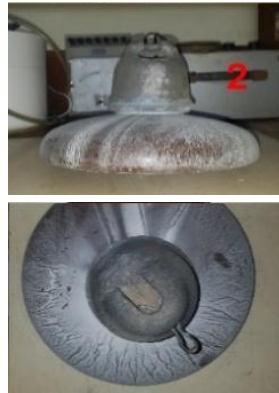

(b) Polluted surface - Ceramic insulator

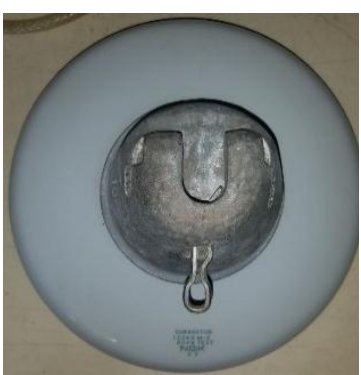

(c) Clean surface - SGI

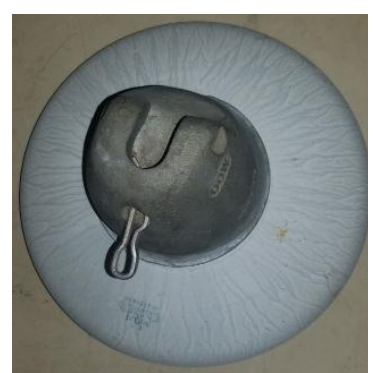

(d) Polluted surface SGI

Figure 1. Samples Used for Laboratory Testing

These samples are subjected to tests under artificial tropical condition, along with clean fog and salt fog (of $20 \mathrm{mS}$ conductivity) condition in a chamber with size of $(1.2 \times 1.2 \times 1.5) \mathrm{m}$, according to IEC 60-1 (1989) [12-13]. The temperature control is installed in the chamber while the humidity is adjusted through an external humidifier. Artificial pollution was applied according to IEC 507, where $40 \mathrm{~g}$ of kaolin was dissolved in 1 litre of water resulting pollutant solutions with conductivity of $3,6 \mathrm{mS}$. Then $12 \mathrm{~g} / \mathrm{L}$ of $\mathrm{NaCl}$ was added to the solution to get the varied desirable value of conductivity [14]. For test, a $50 \mathrm{~Hz}$ AC voltage with range 5 to $20 \mathrm{kV}$ was applied to the sample under various environmental conditions as shown in Table 1.

Table 1. Environmental Condition for Each Tests

\begin{tabular}{|c|c|c|c|c|c|}
\hline No. & Sample & $\begin{array}{l}\text { Chamber } \\
\text { Condition }\end{array}$ & $\begin{array}{c}\text { Room } \\
\text { Temperature }\end{array}$ & $\begin{array}{l}\text { Room } \\
\text { Humidity }\end{array}$ & $\begin{array}{l}\text { Applied } \\
\text { Voltage }\end{array}$ \\
\hline (a) & Clean & & \multirow{4}{*}{$28-32{ }^{\circ} \mathrm{C}$} & \multirow{4}{*}{$90-95 \%$} & \multirow{4}{*}{$5-40 \mathrm{kV}$} \\
\hline (b) & $\begin{array}{l}\text { Polluted } \\
\text { (Kaolin-Salt } 5 \mathrm{mS} \text { ) }\end{array}$ & Clean Fog & & & \\
\hline (c) & Clean & \multirow[b]{2}{*}{$\begin{array}{l}\text { Salt Fog } \\
(20 \mathrm{mS})\end{array}$} & & & \\
\hline (d) & $\begin{array}{l}\text { Polluted } \\
\text { (Kaolin-Salt } 5 \mathrm{mS} \text { ) }\end{array}$ & & & & \\
\hline
\end{tabular}

The test is carried through an experimental circuit as shown in Figure 2.

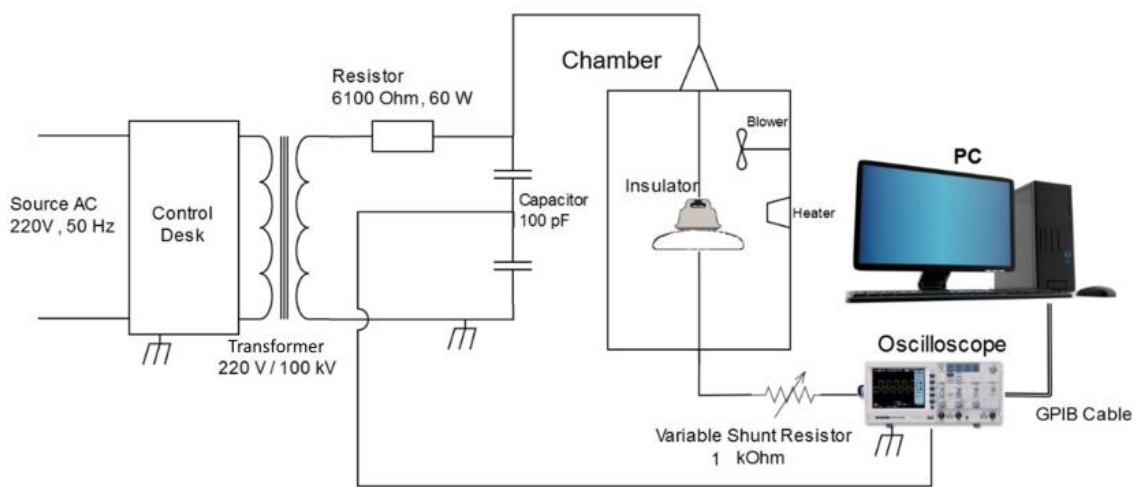

Figure 2. Experimental Setup Circuit for Laboratory Test

The data measured from each tests are leakage current, surface temperature, and hydrophobicity. There are four parameters that were observed from leakage current output data 
which are LC magnitude, THD value, dominant harmonic, and the waveform itself. Surface temperature was measured and captured using FLIR camera, while hydrophobicity is monitored by measuring the contact angle of a water drop on the insulator surface that is captured through a camera.

\section{B. LC Measurement for Field-Aged RTV Silicone Rubber Coated Insulator}

Another experiment that was carried in the field are LC measurement comparison of uncoated and RTV silicone rubber coated insulators. The experiment was conducted on 12 post-pin type outdoor ceramic insulators that have been installed in a substation in Pangandaran coastal area since 2011. The LC measurements were taken every 1-2 years until the last measurement that was in July 2017 [15-17]. Half of the insulators are coated with RTV silicone rubber and the others are not, as shown in Figure 3.

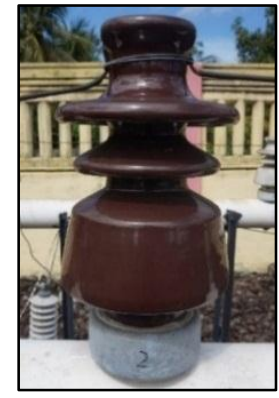

(a)

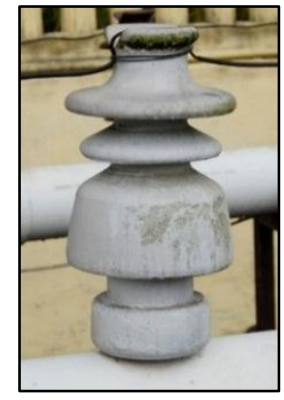

(b)

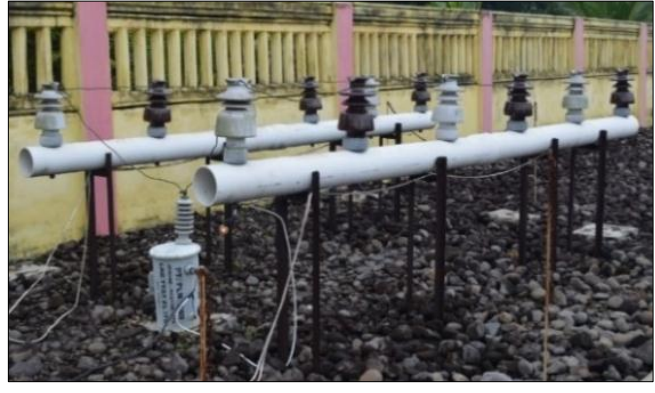

(c)

Figure 3. Samples for Field Experiment: (a) Uncoated Insulator, (b) Coated Insulator, and (c) Installation of Uncoated \& Coated Insulators in field

The insulators are constantly given an $11 \mathrm{kV}$ rms voltage supply. Each measurement was carried out in the afternoon where the temperature was the highest $\left(35.5-40{ }^{\circ} \mathrm{C}\right)$ and the humidity was relatively low (42-53\%) compared to the other times of the day.

\section{Simulation on Outdoor Insulator}

In order to be able to identify the condition of insulators prior to flashover, computer simulation on electrical equivalent circuit of outdoor insulator using ATPDraw software is conducted to obtain electrical properties of LC waveform in various environmental conditions. In this simulation, the key parameters of the electrical equivalent circuit of outdoor insulators such as capacitance, nonlinear resistance, and number of arc models are changed and adjusted so that similar waveforms of each type resulted from the experiments can be acquired. Figure 4 shows the electrical equivalent circuit of outdoor insulator used in this simulation, which is the Suwarno model $[3,18]$.

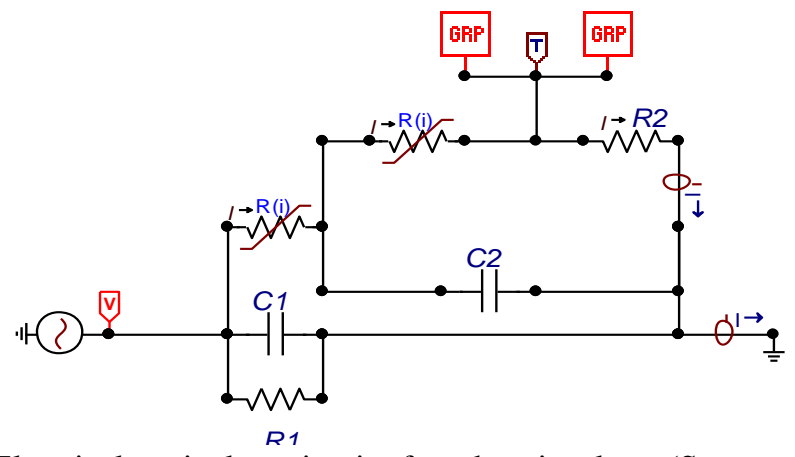

Figure 4. Electrical equivalent circuit of outdoor insulator (Suwarno model) ${ }^{[2]}$ 


\section{Experiment and Simulation Result}

\section{A. Leakage Current Measurement}

1) Laboratory Test for Ceramic and Semiconducting Glazed Insulators (SGI)

LC waveforms for each ceramic insulator and SGI under various environmental condition are shown in Figure 5 and Figure 6 respectively. From Figure 5, it can be seen that for ceramic insulator, the LC waveforms are mostly different toward the condition of insulator surface. Clean samples in either clean or salt fog condition tend to have only slightly distorted waveform on the peaks started from $25-30 \mathrm{kV}$ applied voltage. Meanwhile polluted samples already have slightly distorted waveform on the peaks at $5 \mathrm{kV}$ applied voltage, and the distortion is getting larger at $25 \mathrm{kV}$ (under salt fog condition) and $35 \mathrm{kV}$ (under clean fog condition) applied voltage.

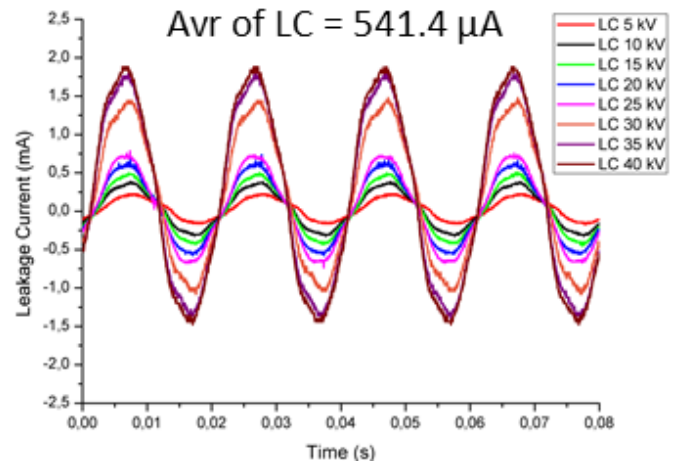

(a) Clean sample - Clean Fog

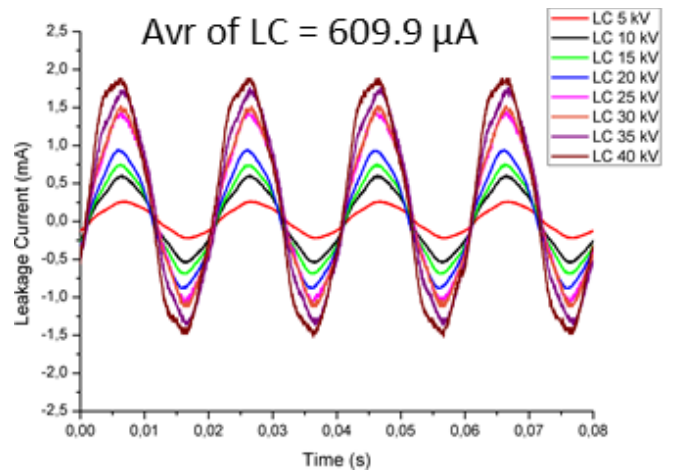

(c) Clean Sample - Salt Fog

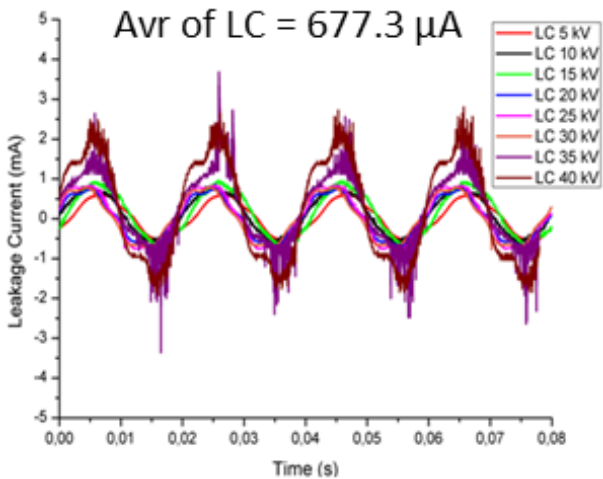

(b) Polluted Sample - Clean Fog

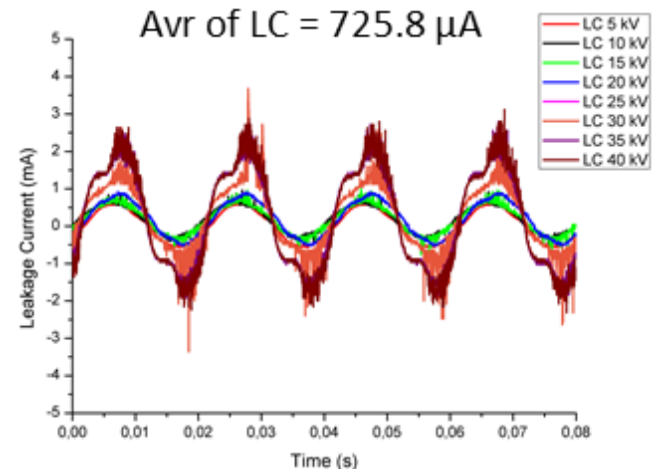

(d) Polluted Sample - Salt Fog

Figure 5. LC waveform measurement result for ceramic insulator under various environmental condition

On the other side, as seen from Figure 6, despite the difference in the LC magnitude, the sinusoidal LC waveform of SGI remain unchanged under any environmental condition. For both types of insulator, the average of LC magnitude goes from the smallest to the largest with the following order: clean sample under clean fog condition, clean sample under salt fog condition, polluted sample under clean fog condition, and polluted sample under salt fog condition. This result has shown that the pollutants that lay on the insulator surface have more impact to the LC flow than the pollutants in the surrounding atmosphere. 


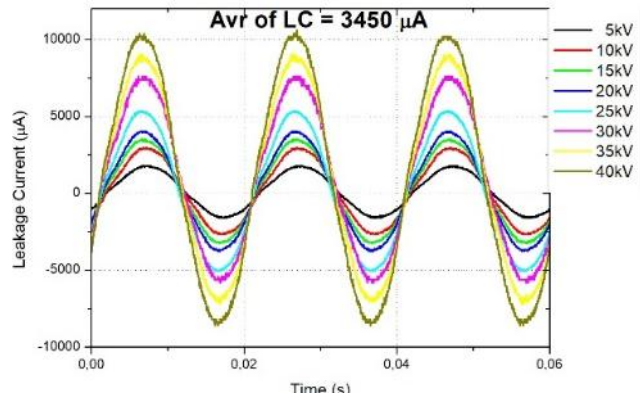

(a) Clean sample - Clean Fog

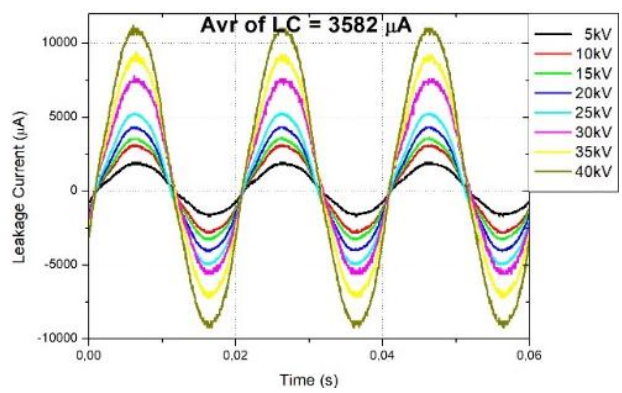

(c) Clean Sample - Salt Fog

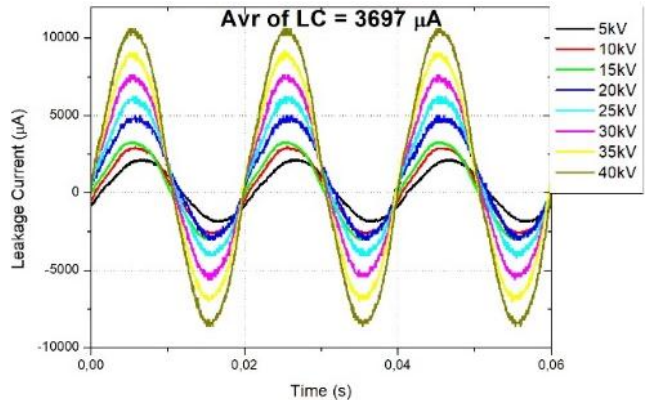

(b) Polluted Sample - Clean Fog

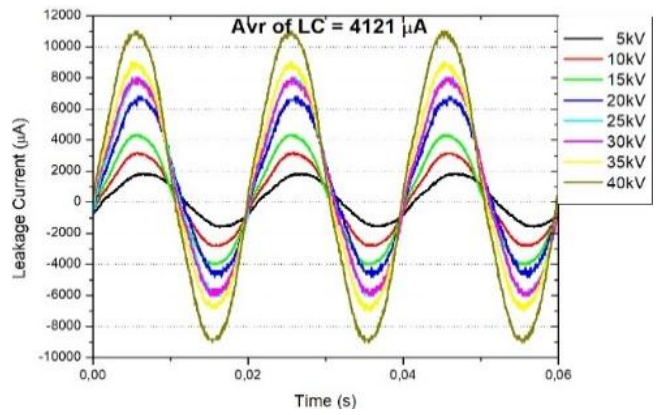

(d) Polluted Sample - Salt Fog

Figure 6. LC waveform measurement result for SGI under various environmental condition

Another parameter for comparison is the cross product between LC magnitude and THD value. Contrary to the magnitude, THD value usually tends to decrease against the LC magnitude. This is because the fundamental components increase faster than the increase in harmonics components so that THD value shrinks when there is a great increase of leakage current, and vice versa. However, when pollutant distribution among samples are not uniform, which are more likely to happen, combined by humidity factor, THD value could quite fluctuate. Thus, it is more reliable to see the LC characteristics from the cross product of LC magnitude and THD. This parameter has shown a better correlation to the insulator conditions in the past research due to the distribution of artificial pollutant can be quite varied which means fluctuated THD [19].

The LC magnitude and the average cross product of LC Magnitude and THD comparison between ceramic insulator and SGI under each environmental condition are shown in Figure 7. Figure 7 clearly shows that LC magnitude increase along with increased apply voltage for any samples under any environmental condition. Moreover, the Figure above pointed out that the range of LC magnitude for ceramic insulator and SGI is obviously different, where the maximum LC of SGI can reach up to seven times of LC of ceramic insulator. With applied voltage ranging from 5 to $40 \mathrm{kV}$, ceramic insulator has LC magnitude of $130-1300 \mu \mathrm{A}$, while SGI has LC magnitude of $950-7000 \mu \mathrm{A}$. This is caused by the characteristic of semiconducting glazed layer that is more conductive than ceramic material, allowing larger LC flow on the insulator surface. 


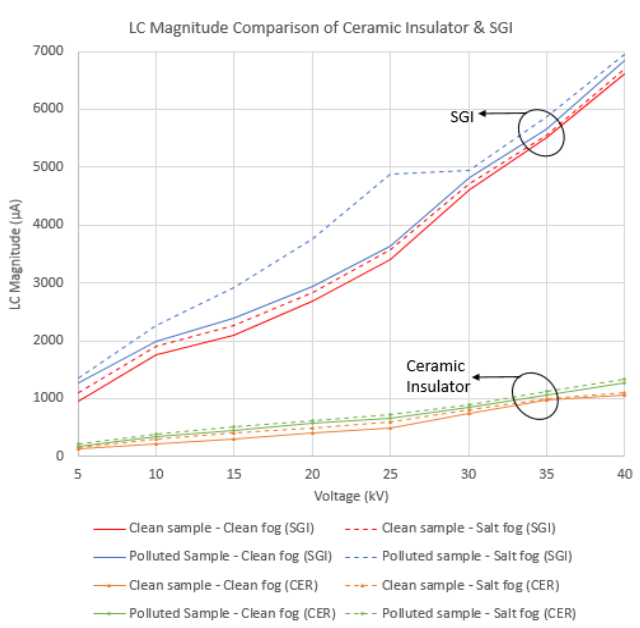

(a)

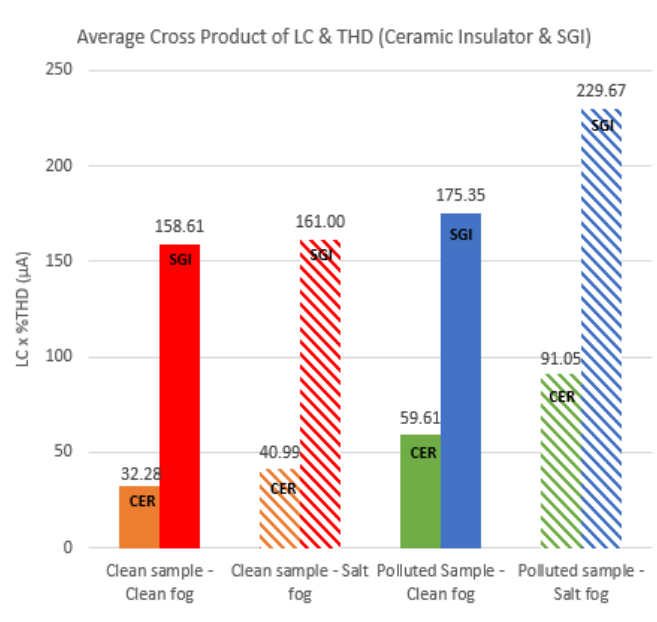

(b)

Figure 7. LC Magnitude comparison of ceramic insulator \& SGI:

(a) LC Magnitude, (b) Average cross product of LC Magnitude \& THD

For each type of insulator, both the LC magnitude only and the average cross product of LC magnitude and THD shows the same trend. Their values from clean samples are smaller than of polluted samples. Those parameter values of both samples under clean fog condition are also smaller than under salt fog condition. The largest LC magnitude is found for polluted sample under salt fog condition, while the smallest is found for clean sample under clean fog condition. It is consistent with the result from Figure 5 and 6, where the pollutant stick on the insulator surface causes larger LC flow on the insulator surface. Humidity especially with air pollution also causes large LC flow, but the impact is not as high as the pollutant that have direct contact to the insulator surface. The largest LC flow is surely found on the combination of both condition, which is polluted sample under salt fog condition.

The polluted samples contain many harmonic components and even discharge. The amount of kaolin-salt pollution has increased the surface conductivity and reduced the hydrophobicity. As a result, the cement that traps water forms a conductive layer, hence larger LC flow occured on the insulator surface. When this continuously happens, continuous dry band is started forming which leads to discharge. The process of discharge is characterized by the formed pulses in the LC waveform. This also causes harmonic components other than the fundamental appear. Salt fog conductivity also affects the magnitude of LC since the magnitude of LC under salt fog condition is higher than clean fog condition.

\section{2) LC Measurement for Field-Aged RTV Silicone Rubber Coated Insulator}

The LC measurement for field-aged RTV silicone rubber coated and uncoated ceramic insulator has been carried out from the year of 2012 to 2017, with result as shown in Figure 8. The graph shows the average values of LC magnitude measured from all pairs of coated or uncoated insulators. The result indicates that along the aging, the LC magnitude tends to increase which means the insulator performances are inevitably decreasing. However, the $5^{\text {th }}$ year measurement shows a different result where the LC magnitude is lower than the previous year. It is most probably caused by the environmental condition that was cleaner due to the rainfall in the previous night, where it is known that insulator can have its natural self-cleaning method through the rain, which also can reduce the leakage current afterwards. 


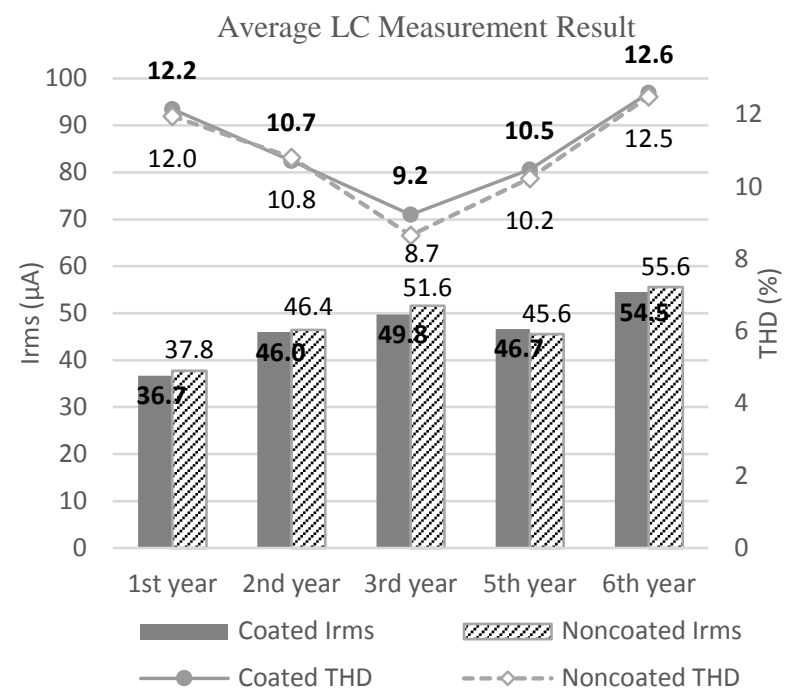

Figure 8. LC Measurement Result on Field-Aged Insulators

Contrary to the LC Magnitude, the THD value constantly decreases from the 1st to the 3rd year and increases from the 3 rd to the $5^{\text {th }}$ year. Seen from the THD equation, when LC magnitude is high, the fundamental harmonic is high as well, thus the ratio between total sum of all harmonics and its fundamental, also known as THD value, would become smaller. However, in the $6^{\text {th }}$ year, the THD value increased from the previous year along with the increase of LC magnitude. It can be caused by the denser pollutant distribution on the insulator surface than the previous year, which suggests a degradation in the insulator performance.

From the different types of insulator point of view, Figure 8 also shows that coated insulator have constantly lower LC magnitude as well as THD value of than uncoated insulators along the aging. An exception is again found in the $5^{\text {th }}$ year, where the previously mentioned rain could cause different pollutant distribution between coated and uncoated insulators. This factor can also be an answer to the difference in LC magnitude at that time of measurement, where the environmental elements such as humidity level and pollutant distribution on the insulator surface can alter a change in LC magnitude as well as THD value [20-21]. In this whole field aging process, the varied pollutant distribution on the insulator surface can be caused by the rain or the wind. Consequently, unexpected results of LC measurement may occur during the aging which mostly are the impact of the environmental condition during the experiments.

\section{B. Surface Temperature}

Aside from leakage current, surface temperature is another parameter that is investigated in this study. The measurement result using FLIR camera is captured and sample at $40 \mathrm{kV}$ supplied voltage are taken as shown in Figure 9. It shows that at $40 \mathrm{kV}$ applied voltage, which is the highest supply voltage applied in this experiment, for both types of insulator, the same as leakage current trend, the temperature characteristic according to various environmental condition goes from the largest to the lowest value with following order: polluted sample under salt fog condition, polluted sample under clean fog condition, clean sample under salt fog condition, and clean sample under clean fog condition. This is because the surface temperature is affected directly by the leakage current flow on insulator surface. 


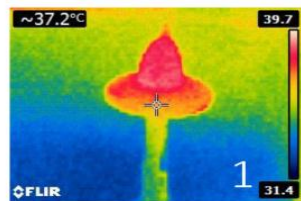

1) Clean Sample - Clean Fog

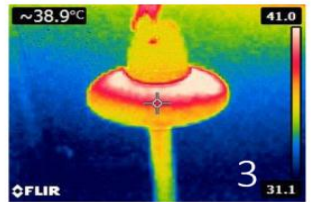

3) Clean Sample - Salt Fog

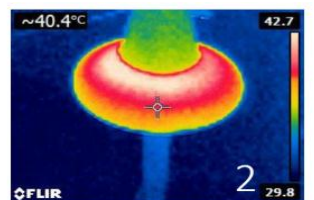

2) Polluted Sample - Clean Fog

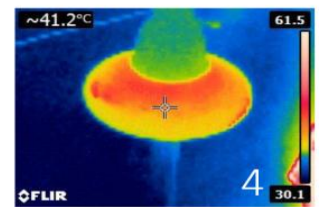

4) Polluted Sample - Salt Fog

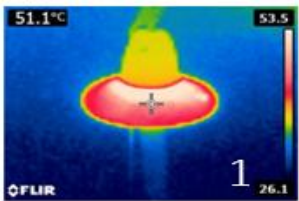

1) Clean Sample - Clean Fog

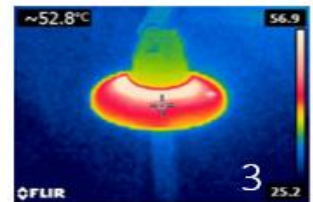

3) Clean Sample - Salt Fog

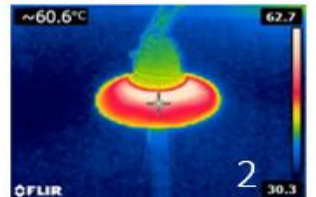

2) Polluted Sample - Clean Fog

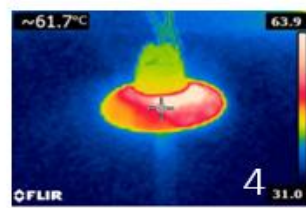

4) Polluted Sample - Salt Fog

(b) SGI

(a) Ceramic insulator

Figure 9. FLIR Camera result at $40 \mathrm{kV}$ applied voltage

Figure 10 shows the surface temperature characteristics against increased supply voltage for ceramic insulator and SGI. The temperature clearly increase along with increased applied voltage as well as LC magnitude. Compared to ceramic insulator, the range of temperature under various environmental condition of SGI is higher than of ceramic insulator by about $10-20^{\circ} \mathrm{C}$. This phenomenon is caused by the LC flow in the semiconducting glazed layer that prevents condensation and humidity effect, so the larger LC magnitude flow on the surface, the higher temperature it reaches.

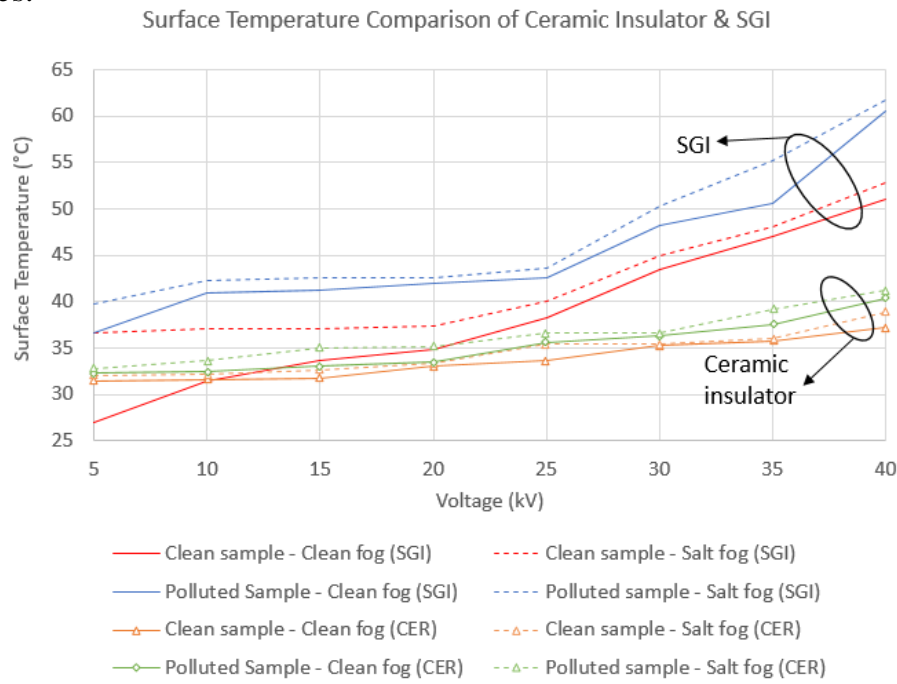

Figure 10. Surface temperature characteristics of ceramic insulator and SGI

Regarding field experiment of RTV silicone rubber coated and uncoated insulators, the actual environmental condition had real impact to the measurement result, since the weather actually caused heating and cooling process on the insulator surface. The insulator surface condition would further affect the insulator thermal characteristic [22]. The insulator thermal characteristic in this experiment is shown in Figure 11. 


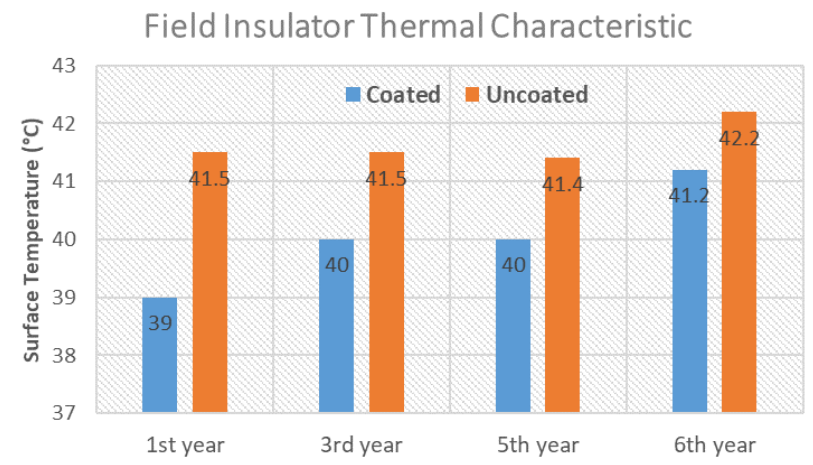

Figure 11. Thermal measurement result of field-aged RTV silicone rubber coated and uncoated insulators

From the above Figure, the RTV silicone rubber coated insulators successfully maintains about $1-2.5^{\circ} \mathrm{C}$ lower surface temperature than uncoated insulators from time to time, although it is also undeniable that the surface temperature of the insulator themselves are increasing along with the aging. This is proportional to the increase trend of LC on insulators surface during the aging process due to the degradation of insulator surface, hence the older the insulators get, the higher the temperature each of the insulator reaches.

\section{Hydrophobicity}

Hydrophobicity is another characteristic that can be measured on an insulator surface through parameter of contact angle. The hydrophobicity on an insulator surface affects the water content on the insulator surface that can cause a change on surface conductivity, hence it influences the LC magnitude. The hydrophobicity measurement results are shown in Table 2.

Table 2. Contact angle measurement result of ceramic insulator and SGI

\begin{tabular}{|c|c|c|c|c|}
\hline \multirow{2}{*}{ Condition } & \multicolumn{2}{|c|}{ Ceramic Insulator } & \multicolumn{2}{|c|}{ SGI } \\
\hline & Clean sample & Polluted sample & Clean sample & Polluted sample \\
\hline $\begin{array}{l}\text { Before LC } \\
\text { Experiment }\end{array}$ & & & & $\begin{array}{l}\text { Clean fog }=40^{\circ} \\
\text { Salt fog }=35^{\circ}\end{array}$ \\
\hline $\begin{array}{l}\text { After LC } \\
\text { Experiment } \\
\text { (Clean fog) }\end{array}$ & & & & $\underset{25^{\circ}}{\lambda}$ \\
\hline & $\Delta \angle=1.21^{\circ}$ & $\Delta \angle=7.66^{\circ}$ & $\Delta \angle=5^{\circ}$ & $\Delta \angle=15^{\circ}$ \\
\hline $\begin{array}{l}\text { After LC } \\
\text { Experiment } \\
\text { (Salt fog) }\end{array}$ & & & & $\$$ \\
\hline & $\Delta \angle=5.2^{\circ}$ & $\Delta \angle=8.3^{\circ}$ & $\Delta \angle=10^{\circ}$ & $\Delta \angle=5^{\circ}$ \\
\hline
\end{tabular}

Both types of insulators show that contact angle in any condition is below $90^{\circ}$, which shows that both insulators have more of hydrophilic characteristic, and seen from the initial condition, the SGI is more hydrophobic than the ceramic insulator. The LC is usually capacitive when an insulator is hydrophobic and causes the waveform to remain sinusoidal [23]. This will relate to the discussion on simulation of SGI afterward. The changes (delta) of contact angle before and 
after LC test result show that the presence of pollutants on the insulator surface can cause the reduction of hydrophobicity up to $8.3^{\circ}$ for ceramic insulator and $15^{\circ}$ for SGI. For salt fog experiments, the change of contact angle is larger than clean fog experiments, except for SGI with polluted surface whose result is the opposite. This shows that both pollutant presence in the surrounding air and on the insulator surface have effects in reducing the hydrophobicity of insulator surface.

For field-aged insulator experiments, the contact angle measurement result along the aging process is shown in Table 3.

Table 3. Contact angle measurement result of field-aged RTV silicone rubber coated and uncoated insulators

\begin{tabular}{|c|c|c|c|c|}
\hline $\begin{array}{c}\text { Aging } \\
\text { Period }\end{array}$ & $1^{\text {st }}$ Year & $3^{\text {rd }}$ Year & $5^{\text {th }}$ Year & $6^{\text {th }}$ Year \\
\hline $\begin{array}{c}\text { Coated } \\
\text { insulator }\end{array}$ & as & & & \\
\hline $\begin{array}{c}\text { Cont. } \\
\text { Angle }\end{array}$ & $90-100^{\circ}$ & $76-90^{\circ}$ & $57-80^{\circ}$ & $51-67^{\circ}$ \\
\hline $\begin{array}{c}\text { Uncoated } \\
\text { insulator }\end{array}$ & $30-35^{\circ}$ & $25-30^{\circ}$ & $5-22^{\circ}$ & $0-7^{\circ}$ \\
\hline $\begin{array}{c}\text { Cont. } \\
\text { Angle }\end{array}$ & 30 & & & \\
\hline
\end{tabular}

Table 3 shows that the field-aging process with constant charged voltage as well as constant high temperature and humidity weather have obviously great impact on hydrophobicity reduction of the insulator surface. It also shows that how much improvement on insulator performance when RTV silicone rubber coating is applied to an insulator surface, especially in the first year where the coated insulator was clearly hydrophobic. Up until the $6^{\text {th }}$ year, coated insulator also still shows higher hydrophobicity with contact angle of $51-67^{\circ}$, whereas uncoated insulators already turned into completely hydrophilic with contact angle of $0-7^{\circ}$. Coated insulator surface has hydrophobic layer that can reduce water content on the insulator surface so that the pollutant that falls on the insulator surface can be easily carried by the water through natural self-cleaning process of the insulator. In high humidity weather, the water content on the insulator surface is quite high as well that it increases surface conductivity. Since the aged uncoated insulator is already hydrophilic, the water is easily absorbed, hence when the insulator is charged, leakage current flows and form dry bands. Meanwhile, coated insulator is more hydrophobic, thus the leakage current flow is also smaller. After the humidity turns back to normal, the coated insulator surface becomes dryer than the uncoated ones, resulting lesser LC flow. Therefore, eventually at the end of the aging process, coated insulator successfully maintained its high hydrophobicity level of the insulator surface.

\section{Simulation of Leakage Current Waveform}

\section{1) Ceramic insulator under various environmental condition}

From the whole experiment results, some samples of LC waveform are simulated using ATPDraw software to get the electrical equivalent circuit parameters and study on the characteristics. For ceramic insulator, the LC waveforms at $40 \mathrm{kV}$ applied voltage are taken into simulation, with results as shown in Table 4 . The similarity of the simulated and experimental leakage currents was indicated in the magnitude, THD and dominant harmonic components. 
Table 4. Simulated LC waveform of ceramic insulator at $40 \mathrm{kV}$ applied voltage

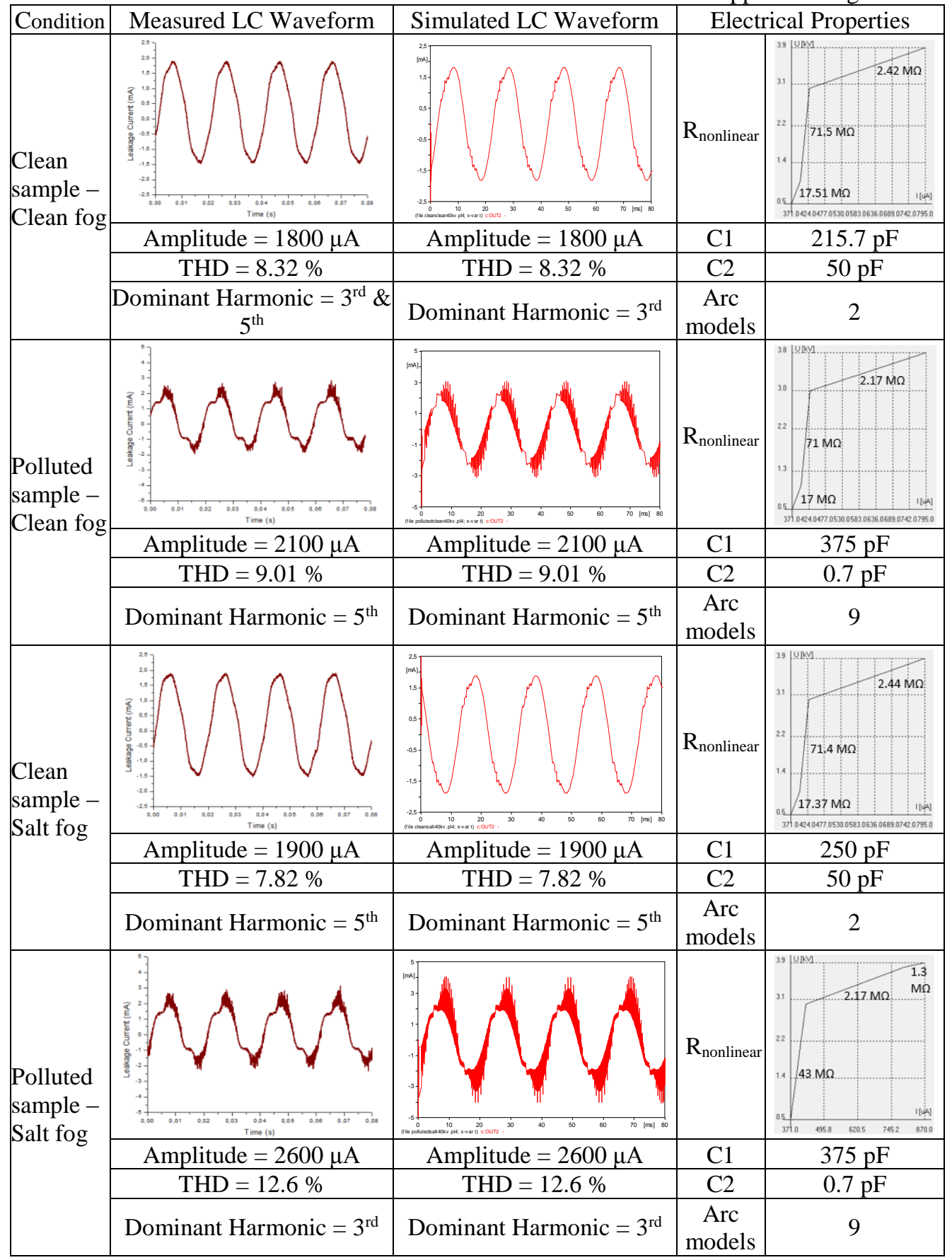

The table shows that on the highest supplied voltage of $40 \mathrm{kV}$, the experiment of polluted samples which shows higher LC magnitude and THD value, have lower piecewise resistances than the clean samples with higher insulator capacitance, allowing larger magnitude of LC flow on the insulator surface. Meanwhile, the frequent arcs that occur on LC waveform of polluted samples are represented by 9 arc models and dry band capacitance of $0.7 \mathrm{pF}$. On the other side, LC waveforms of clean samples at the same applied voltage only have slight discharge on the 
peak of the waveform, hence represented only by 2 arc models with dry band capacitance of 50 $\mathrm{pF}$.

2) Semiconducting glazed insulator under various environmental condition

Simulated LC waveforms of SGI are shown in Table 5 below.

Table 5. Simulated LC waveform of SGI at $40 \mathrm{kV}$ applied voltage

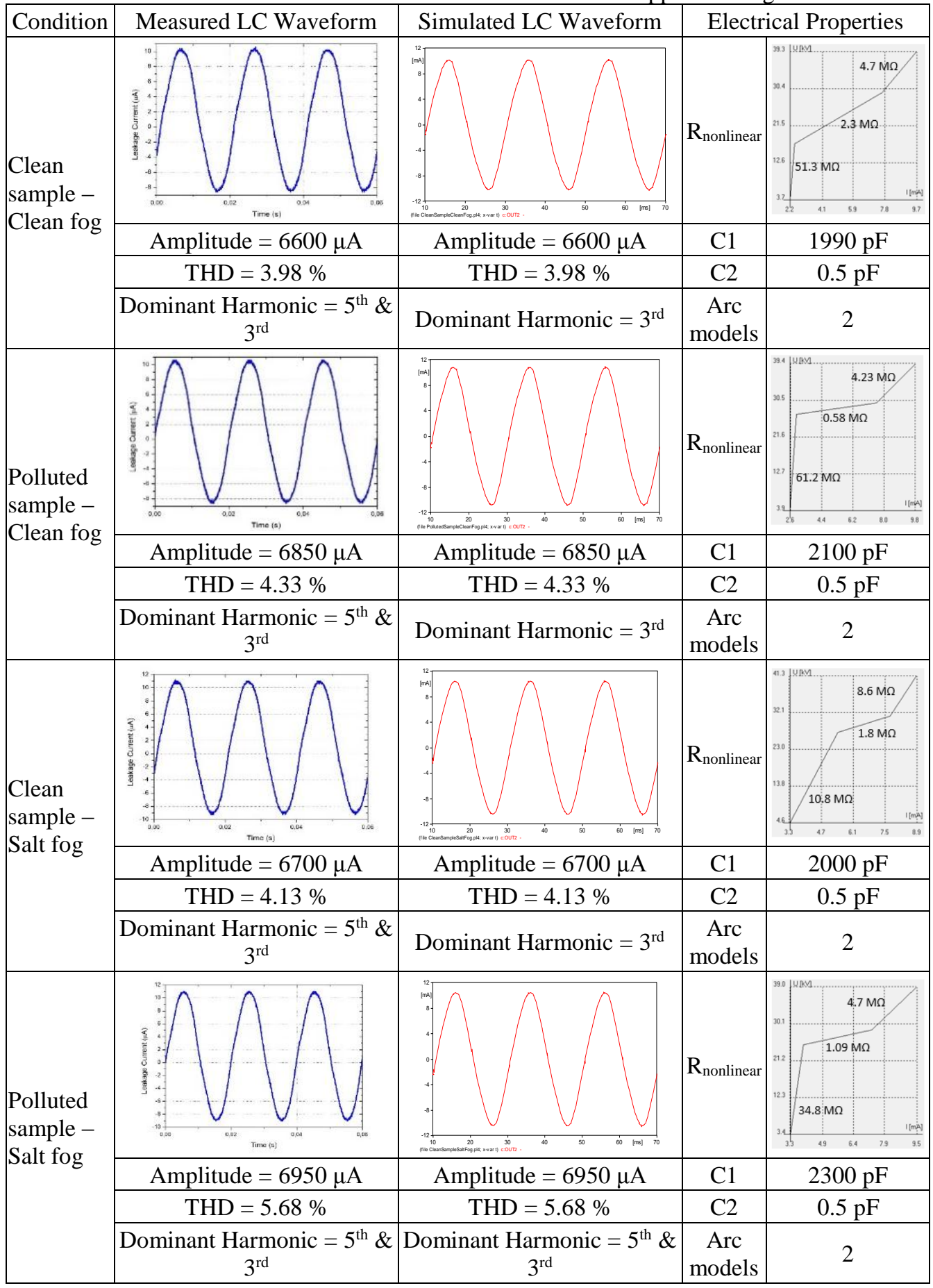


From the table, it is known that the sinusoidal LC waveform of SGI can be recreated through simulation with the exact same value for parameters such as amplitude, THD, and dominant harmonic. This sinusoidal LC waveforms have large magnitude and very small THD value (with range 4 to $6 \%$ only), which is here formed by smaller value of piecewise nonlinear insulator resistance $(\mathrm{R}=10-50 \mathrm{M} \Omega)$, higher insulator capacitance $(\mathrm{C} 1=1900-2300 \mathrm{pF})$ and few arc models (only 2 arc models required), compared to ceramic insulator $(\mathrm{R}=40-70 \Omega ; \mathrm{C} 1=200$ $-400 \mathrm{pF}$ ). Despite the difference in magnitude, the LC waveforms under every environmental conditions are similar, thus the insulator surface resistance nonlinearity and number of arc models are all similar as well.

\section{3) Field-aged RTV silicone rubber coated and uncoated ceramic insulator}

From the whole field aged insulator experiment results, a pair of coated and uncoated insulator is taken as sample from each year (total eight samples) whose LC waveforms are recreated through computer simulation, by adjusting the electrical equivalent circuit parameters, such as capacitance, nonlinear resistance, and number of arc models. Table 6 shows the comparison of measured LC waveform and simulated LC waveform along with its key waveform parameters, such as LC magnitude, THD, and dominant harmonic. In addition, Table 7 shows the electrical equivalent circuit parameters that produce the respected LC waveforms.

In Table 6, the most noticeable changed characteristic is the LC waveforms that are getting more distorted along the years. The distortion level on the waveform crest can be shaped by arc models used in the simulation. It only requires 1 to 2 arc models to form slightly distorted waveforms such as in the $1^{\text {st }}$ and the $3^{\text {rd }}$ year, while more arc models (5) are added to form more distorted waveforms such as in the $5^{\text {th }}$ and the $6^{\text {th }}$ year, where the insulators have aged for quite a while. The next changed characteristic of the waveform that can be clearly seen is the LC amplitude, which also increase along the aging process. In each year, where the LC amplitude of coated insulator is lower than the uncoated insulator, the nonlinear resistance is the parameter that correspond to this result, as shown in Table 7. The nonlinear resistors with higher piecewise resistance have resulted in lower LC magnitude which is valid for both the different condition of LC magnitude along the aging process, as well as the different condition of LC magnitude between coated and uncoated insulators. Nevertheless, although the magnitude is different every year, the LC waveform between coated and uncoated insulators at the same measurement time is always similar. In simulation, this is indicated by the similar nonlinear resistance characteristic curve.

In the simulation, the insulator capacitance $(\mathrm{C} 1)$ that have impact on the phase difference between the LC and the arc current has value of $4 \mathrm{pF}$ in the $1^{\text {st }}$ and the $5^{\text {th }}$ year, while higher value of $8 \mathrm{pF}$ and $7.8 \mathrm{pF}$ are required for the $3^{\text {rd }}$ and the $6^{\text {th }}$ year respectively. The resulted phase difference then consequently determine the arc positions against the LC waveform. On the other hand, the dry band capacitance $(\mathrm{C} 2)$ are the same for all waveforms, except in the $5^{\text {th }}$ year. As previously discussed, at that time the humidity and pollutant distribution on the insulator surface result in distinct environmental condition compared to the other years which have relatively low humidity, which also corresponds to a different dry band capacitance.

The dominant harmonic number that occurred in all LC waveforms are the $5^{\text {th }}$, as it greatly affects the THD value [5]. The $2^{\text {nd }}$ and $3^{\text {rd }}$ dominant harmonic varies for each measurement, which are the $7^{\text {th }}, 3^{\text {rd }}$, or $11^{\text {th }}$, but mostly has insignificant magnitude compared to the $5^{\text {th }}$ harmonic. This condition is resulted by the combined parameters of nonlinear resistance, capacitance and arc models. 
Table 6. The comparison of LC waveform from experiments and simulation result

\begin{tabular}{|c|c|c|c|c|c|c|c|c|}
\hline \multirow{2}{*}{$\begin{array}{l}\text { Aging } \\
\text { Period }\end{array}$} & \multicolumn{4}{|c|}{ Coated Insulator } & \multicolumn{4}{|c|}{ Uncoated Insulator } \\
\hline & & & & & ent & & & \\
\hline & 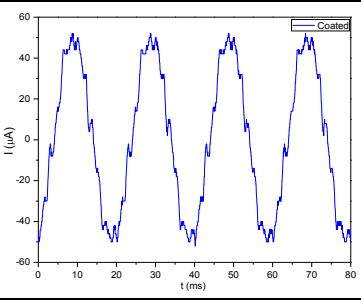 & 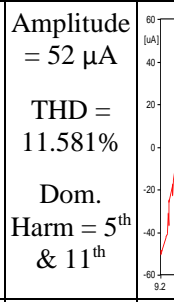 & $\int_{0}^{\infty}$ & $\begin{array}{c}\text { THD }= \\
11.581 \% \\
\text { Dom. } \\
\text { Harm }=5^{\text {th }} \\
\& 13^{\text {th }}\end{array}$ & E & 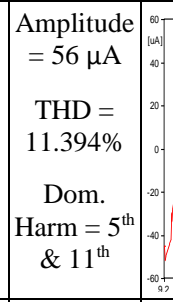 & $\underbrace{400}_{600}$ & $\begin{array}{c}=52 \mu \mathrm{A} \\
\text { THD }= \\
11.394 \% \\
\text { Dom. } \\
\text { Harm }=5^{\text {th }} \\
\& 7^{\text {th }}\end{array}$ \\
\hline & $\underbrace{\substack{1 \\
\text { t(ms) }}}_{-20}$ & 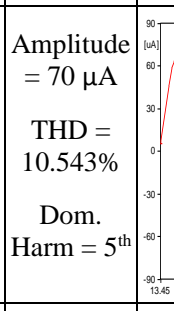 & 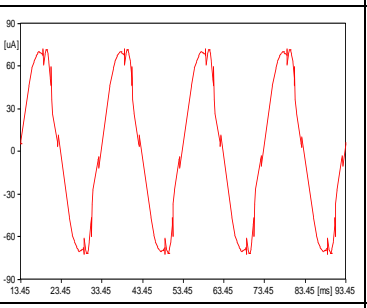 & $\begin{array}{c}\text { Amplitude } \\
=70 \mu \mathrm{A} \\
\\
\text { THD }= \\
10.543 \% \\
\text { Dom. } \\
\text { Harm }=5^{\text {th }}\end{array}$ & $\underset{\substack{\text { tims } \\
i=20}}{2}$ & 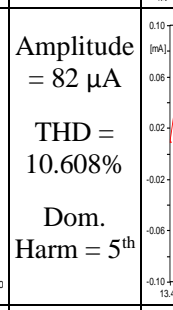 & 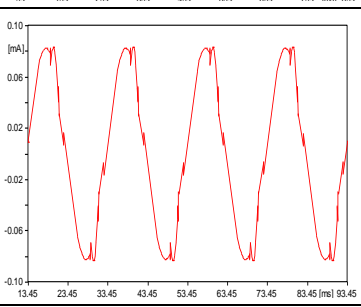 & $\begin{array}{c}=82 \mu \mathrm{A} \\
\text { THD }= \\
10.608 \% \\
\text { Dom. } \\
\text { Harm }=5^{\text {th }}\end{array}$ \\
\hline & 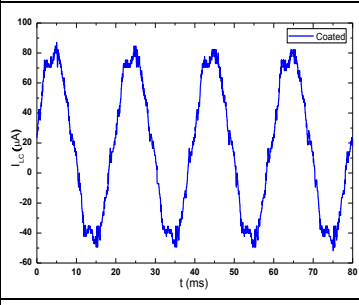 & 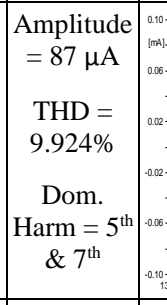 & 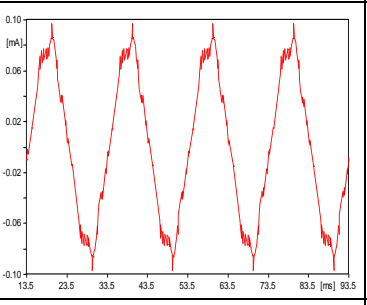 & $\begin{array}{c}=87 \mu \mathrm{A} \\
\mathrm{THD}= \\
9.924 \% \\
\text { Dom. } \\
\text { Harm }=5^{\text {th }}\end{array}$ & $=\underset{10}{20} \underbrace{}_{20}$ & 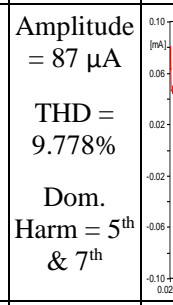 & . & $\begin{array}{l}=8 / \mu \mathrm{A} \\
\mathrm{THD}= \\
9.778 \% \\
\text { Dom. }\end{array}$ \\
\hline If & (10) & 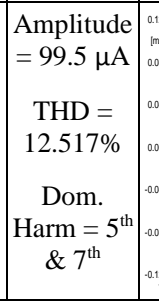 & (1) & $\begin{array}{c}\text { THD }= \\
12.517 \% \\
\text { Dom. } \\
\text { Harm }=5^{\text {th }} \\
\& 7^{\text {th }}\end{array}$ & 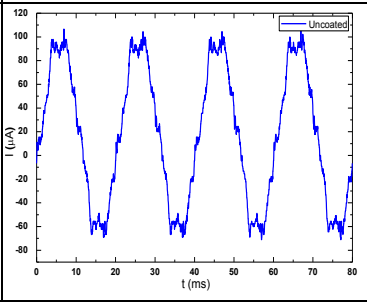 & 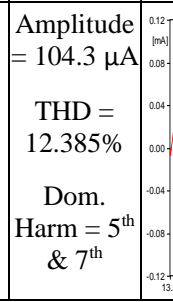 & (1) & $\begin{array}{c}\text { Amplitude } \\
=104.3 \mu \mathrm{A} \\
\text { THD }= \\
12.385 \% \\
\text { Dom. } \\
\text { Harm }=5^{\text {th }} \\
\& 7^{\text {th }}\end{array}$ \\
\hline
\end{tabular}


Table 7. Electrical equivalent circuit parameters for LC waveform of field-aged ceramic insulators

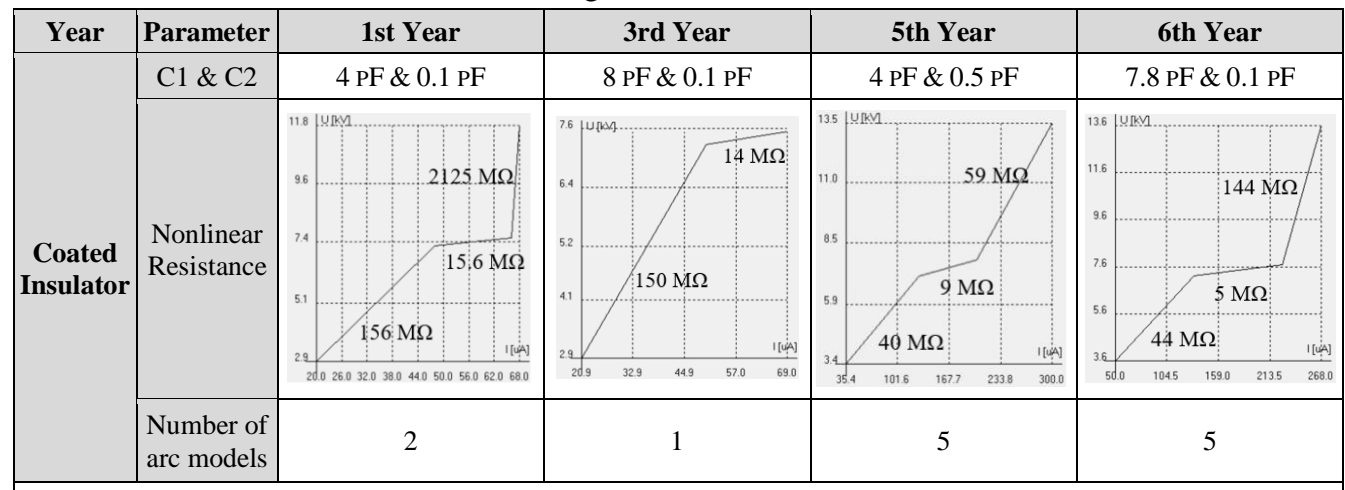

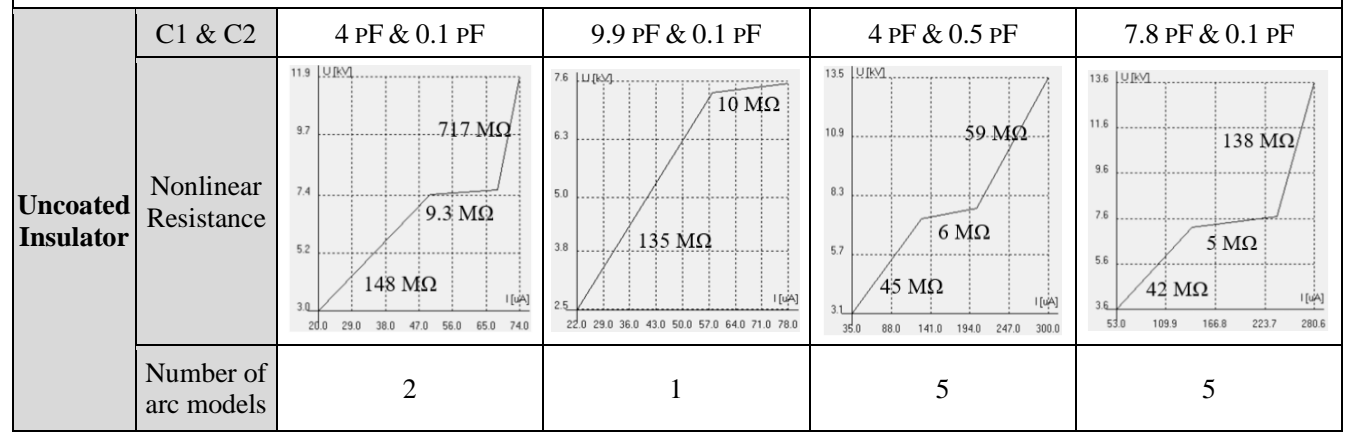

The ultimate purpose of this LC waveform simulation is characterization of LC waveform from different types of insulators, under various environmental conditions as well as during the aging process. It is expected that a certain condition prior to the flashover can be detected beforehand by monitoring this LC waveform. Therefore, a sample of field-aged insulators was brought back to the laboratory and investigated by applying increased supply voltage to represent the aging effect. The experiment shows that under salt fog environmental condition, the LC waveform started to become unsymmetrical where a noticeable discharge occurred on one of the troughs at $40 \mathrm{kV}$ applied. Table 8 shows the details of the simulation result and the electrical equivalent parameters that form the LC waveform on this condition.

Table 8. Experiment and simulated LC waveform of insulator under salt fog condition at $40 \mathrm{kV}$ applied voltage.

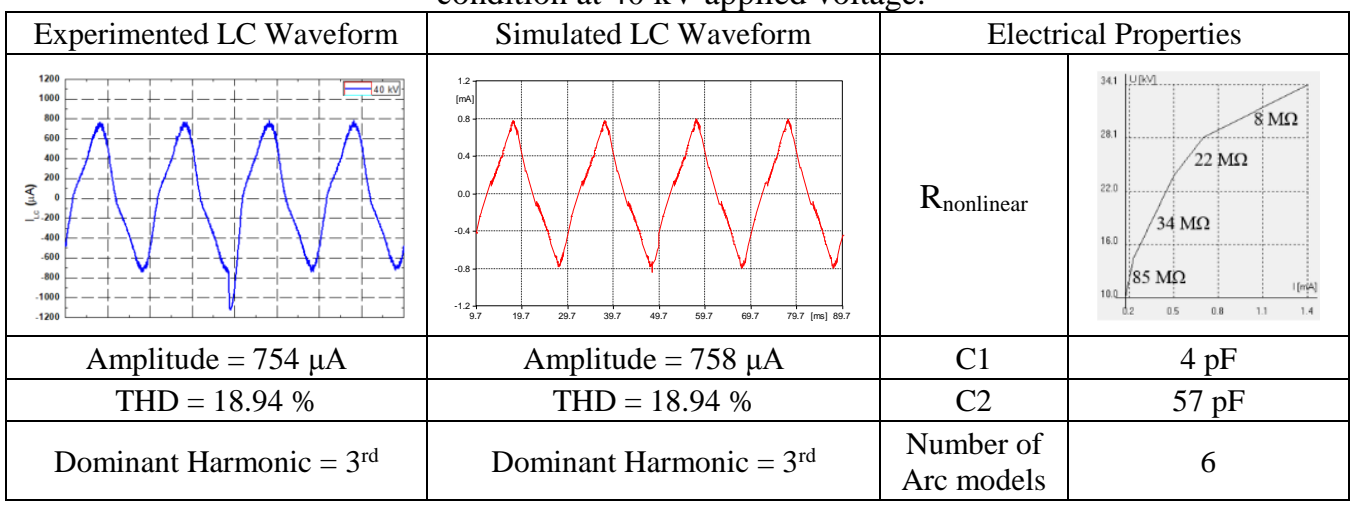


According to the above table, in the condition prior to flashover, the $3^{\text {rd }}$ dominant harmonic number appeared instead of the usual $5^{\text {th }}$. Additionally, many even harmonic numbers started to appear due to the unsymmetrical waveform. The unsymmetrical waveform itself along with the discharge are formed by six arc models in this simulation. The insulator capacitance (C1) in this condition has the usual value, but the dry band capacitance (C2) is much larger than at the operating voltage, which also represents the condition prior to flashover. Consequently, the THD value greatly increased. The nonlinear resistance of the insulator has shown an increased nonlinearity properties than in normal condition as shown in the table.

\section{Conclusions}

This study has shown that LC waveform and magnitude that flows on the insulator surface is strongly affected by the applied voltage, environmental condition, and the condition of the insulator surface itself. Both for ceramic insulator and SGI, along with the increased apply voltage, the LC magnitude and the cross product of LC magnitude and THD value increased with different environmental condition with the presence of pollutant stick on the insulator surface, which has higher impact, followed by the polluted atmosphere (in this case salt fog condition). Specifically for SGI, LC waveforms are generally similar with the sinusoidal applied voltage. The LC waveforms are also symmetrical for positive and negative half cycles and no flashover was observed for applied voltage up to $40 \mathrm{kV}$. Additionally, the surface temperature increases proportionally to the LC magnitude.

The hydrophobicity of insulator surface decrease after the experiments, with the pollutant presence and salt fog condition cause higher reduction compared to the clean samples and in clean fog environment. The observed SGI that has higher hydrophobicity compared to ceramic insulator has been proven as well. On the other hand, field-aged experiment result on RTV silicone rubber coated insulator shows much better result on maintaining its hydrophobicity characteristic compared to field-aged uncoated ceramic insulator. At the end of the $6^{\text {th }}$ year, the difference of contact angle between the two types of insulators can reach up to $50-60^{\circ}$. This proves that less pollutant is likely to stick on coated insulators for long, hence preventing more dry bands to form and cause less leakage current flow on the insulator surface.

Experiment of LC measurement have been conducted on field-aged outdoor ceramic insulators with and without RTV silicon rubber coating in a coastal area. The LC characteristics along the five consecutive years are observed, and the result shows that coated insulators have consistently lower LC magnitude than the uncoated insulators. Quite the opposite, THD value of coated insulators are relatively higher than the uncoated ones, which is caused by the larger magnitude of leakage current has larger fundamental harmonic, resulting lower THD value.

The LC waveforms obtained from all experiments both in the laboratory or in the field have been successfully recreated through computer simulation using ATPDraw software with precise key parameters of LC amplitude, THD, and dominant harmonic. For lab experiments, it shows that SGI is more capacitive than normal ceramic insulator and has lower values of piecewise resistance of the nonlinear resistance, resulting $\mathrm{LC}$ flow on the insulator surface also much higher. Despite the increased applied voltage, SGI shows very little discharge on its LC waveform, hence it has only 2 arc models, while at higher applied voltage, ceramic insulator has many discharges occur along the LC waveform, hence the arc models for this insulator can reach up to 9 arc models.

As for LC waveform on field-aged insulators, the electrical equivalent circuit parameter shows that as the insulator aged, the nonlinearity of resistance characteristic increased but accompanied by decreased value of each piecewise resistance, resulting higher LC magnitude. Number of arc models also increased to obtain more distorted waveforms along the aging of insulator. Meanwhile the capacitance does not vary a lot due to environment and pollutant condition during experiments are relatively similar. 


\section{References}

[1]. Suwarno, "Diagnosis of High Voltage Equipments", Penerbit ITB, Bandung, 2010.

[2]. G. Zhicheng, M. Yingke, W. Liming, L. Ruihai, W. Hua and M. Yi, "Leakage Current and Discharge Phenomenon of Outdoor Insulators" International Journal on Electrical Engineering and Informatics, vol. 1, no. 1, 2009.

[3]. Suwarno and F. Pratomosiwi, "Electrical equivalent circuit of ceramic insulators with RTV silicone rubber coating and computer simulation of leakage currents". WSEAS Transactions on Circuits and Systems, Issue 4, Volume 8, April 2009.

[4]. Suwarno and Ario Basuki Wibowo, "Increasing the performances of various Types Outdoor Insulators by using RTV Silicone Rubber Coating". International Journal on Electrical Engineering and Informatics - Volume 4, Number 4, December 2012.

[5]. Fari Pratomosiwi and Suwarno, "Performance Improvement of the Ceramic Outdoor Insulators Located at Highly Polluted Environment Using Room Temperature Vulcanized Silicone Rubber Coating". International Journal on Electrical Engineering and Informatics - Volume 2, Number 1, 2010

[6]. Suwarno and F. Pratomosiwi, "Computer simulation of leakage current on ceramic insulator under clean fog condition". 3rd Asia International Conference on Modelling \& Simulation, 2009. AMS'09.

[7]. Akio Hayashi, et al., "Evaluation Methods of Contamination Flashover Voltage Performance of Semiconducting Glaze Insulators", 2008.

[8]. O. Elsasser and K. Feser., "Flashover Behavior of Semiconducting Glazed Insulators under Positive Impulse Stress at Different Climatic Conditions", Conference on Electrical Insulation and Dielectric Phenomena, 1999.

[9]. U. Samanmit, et al., "Improvement of Standard Suspension Type Insulator by the Semiconducting Glaze for Pollution Condition", 2007.

[10]. Naufalarizqa R M P, et al., "The Study of Leakage Current Waveform Characteristic in Ceramic Insulator under Artificial Tropical Condition", 2018 12th International Conference on the Properties and Applications of Dielectric Materials (ICPADM), 2018.

[11]. Nike S, et al, "Study on Leakage Current Characteristics and Computer Simulation of Semiconducting Glazed Insulator under Clean and Salt Fog Condition”, 2018 12th International Conference on the Properties and Applications of Dielectric Materials (ICPADM), 2018.

[12]. IEC 601, "High Voltage Test Techniques", IEC International Standard, 1989.

[13]. IEEE Std. 4,"IEEE Standard Techniques for High-Voltage Testing”, 2013.

[14]. IEC 507, "Artificial Pollutant Test on HV Insulator to be used on AC Systems", 1991.

[15]. Dini Fauziah, Heldi Alfiadi, Rachmawati, and Suwarno, "The effect of coating on leakage current characteristic of coast field aged ceramic insulator". 4th International Conference on Electrical Engineering, Computer Science and Informatics (EECSI 2017).

[16]. Rachmawati, Dini Fauziah, Heldi Alfiadi,and Suwarno, "Leakage Current Characteristics Study on Electrical Equivalent Circuit of Field-Aged RTV Silicone Rubber Coated and Noncoated Insulators in a Coastal Area", 2017 International Conference on High Voltage Engineering and Power Systems (ICHVEPS), October 2017.

[17]. Rachmawati and Suwarno." Leakage Current Properties of Field-Aged RTV Silicon Rubber Coated \& Uncoated Ceramic Insulators", 2018 12th International Conference on the Properties and Applications of Dielectric Materials (ICPADM), 2018.

[18]. Waluyo, Parouli M. Pakpahan, and Suwarno, "Study on the electrical equivalent circuit models of polluted outdoor insulators". 8th International Conference on Properties and applications of Dielectric Materials, 2006.

[19]. Suwarno, "Leakage Current Waveforms of Outdoor Polymeric Insulators and Possibility of Application for Diagnostics of Insulator Condition", Journal of Electrical Engineering \& Technology, Vol.1, No. 1, pp. 114-119, 2006. 
[20]. Li, J.Y., Sun, C.X., and Sebo, S.A. (2011): Humidity and Contamination Severity Impact on The Leakage Currents of Porcelain Insulators, IET Generation, Transmission \& Distribution, Vol. 5, Iss. 1, pp. 19-28.

[21]. Tousi A.A., and Mirzaie, M. (2013): Impact of Pollution Location on Time and Frequency Characteristics of Leakage Current of Porcelain Insulator String under Different Humidity and Contamination Severity, Journal of Operation and Automation in Power Engineering Vol. 1, No. 2, Summer \& Fall, Pages: 74-83

[22]. Voslo, WL and Holtzhausen, JP, "The Effect of Thermal Characteristics of Power Line Insulators on Pollution Performance", IEEE Africon, 2002.

[23]. Fernando, M.A.R.M., Gubanski, S.M., "Ageing of Silicone Rubber Insulators in Coastal and Inland Tropical Environment”, IEEE Journal, 2010.
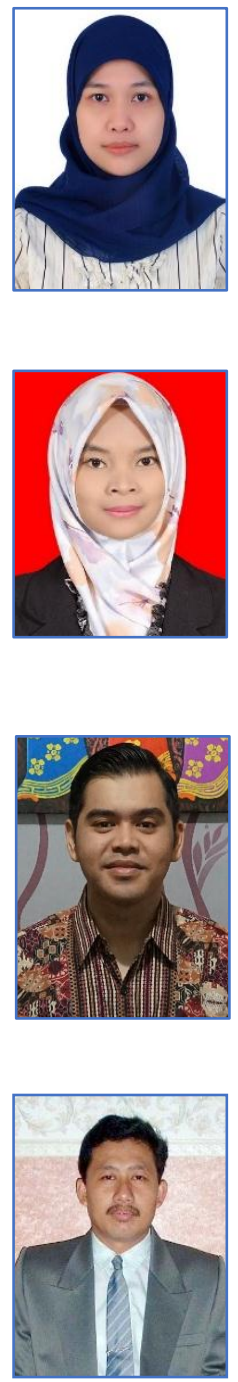

Rachmawati was born in Indonesia in 1988. She received her B.Sc degree from the Department of Electrical Engineering, Institut Teknologi Bandung, Indonesia in 2010 and her M.Eng degree from the Department of Electrical and Communication Engineering, Tohoku University, Japan in 2013. She is currently an academic assistant in Electrical Power Engineering Research Division under School of Electrical Engineering and Informatics (SEEI), Institut Teknologi Bandung.

Nike Sartika was born in Indonesia in 1993. She received her B.Sc degree in electrical engineering education from Universitas Pendidikan Indonesia (UPI) in 2015. Then she recently received her M.Sc degree in electrical engineering from the School of Electrical Engineering and Informatics, Institut Teknologi Bandung in 2018.

Naufalarizqa Ramadha Meisa Putra was born in Indonesia in 1995 . He received his B.Sc degree in electrical engineering from the Faculty of Engineering, Universitas Indonesia in 2016. Then he received his M.Sc degree from the School of Electrical Engineering and Informatics, Institut Teknologi Bandung in 2018, still in the same field.

Suwarno was born in Indonesia in 1965. He received BSc and MSc from The Department of Electrical Engineering, Bandung Institute of Technology, Bandung, Indonesia in 1988 and 1991 respectively. He received $\mathrm{PhD}$ from Nagoya University, Japan in 1996 in the field of High Voltage Electrical Insulation. Prof. Dr. Suwarno is a professor in The School of Electrical Engineering and Informatics, Institut Teknologi Bandung and currently he is the Chairman of Electrical Power Engineering Research Group. Prof. Dr. Suwarno is a senior member of IEEE. 